\title{
Çok Katlı Betonarme Binaların TBDY2018 Kapsamında Tasarlanması: 36 Katlı Bina Örneği
}

\author{
${ }^{1}$ Mahir Alhusni ve ${ }^{* 1}$ Zehra Şule Garip \\ ${ }^{1}$ Faculty of Engineering, Department of Civil Engineering Karabuk University, Turkey
}

\section{Özet}

Ülkemizde nüfus yoğunluğu genel olarak depremselliğin etkili olduğu bölgelerde görülmektedir. Günümüze kadar çok sayıda orta ve büyük şiddetli depremler meydana gelmiştir ve istenmeyen oranda can ve mal kayıpları yaşanmıştır. Bu nedenle deprem etkisine maruz kalacak olan betonarme binaların tasarımında yeterli dayanımın sağlanması ve bunun yanında ekonomi ve konforun da dikkate alınması gerekmektedir. Nüfus yoğunluğunun yüksek olduğu bölgelerde yatay mimarinin dikkate alınmasının ekonomik açıdan zorluk çıkarması nedeniyle dikey mimari tercih edilmektedir. TBDY2018 yönetmeliğine göre bu tarz yüksek binaların tasarımında özel esaslar yer almaktadır. Bu çalışmada betonarme yüksek bir binanın yeterli dayanımı sağlayacak şekilde tasarımı gerçekleştirilmiştir. Tasarım aşamasında uyulması gereken kuralların detaylandırılması amaçlanmıştır. Bu nedenle betonarme bina modeli ETABS2019 bilgisayar paket programı yardımıyla oluşturulmuş ve zaman tanım alanındaki doğrusal olmayan analizleri FNA (Fast Nonlinear Analysis) yöntemi kullanılarak gerçekleştirilmiştir. Analizlerden elde edilen veriler grafikler ve tablolar halinde sunulmuş ve değerlendirilmiştir. Tasarlanan betonarme bina modelinin yönetmelikte istenen kriterleri ve performans hedefini sağladığı görülmüştür. Çalışmanın bir sonraki aşamasında doğrudan integrasyon yöntemi kullanılarak değerlendirme yapilacaktır.

Anahtar Kelimeler: FNA, TBDY-2018, Betonarme Yüksek Binalar.

\begin{abstract}
In our country, population density is generally seen in regions where seismicity is effective. To date, numerous moderate and large earthquakes have occurred and there have been undesirable loss of life and property. Therefore, it is necessary to ensure sufficient strength in the design of reinforced concrete buildings that will be subjected to earthquake effect, as well as to consider economy and comfort. Vertical architecture is preferred because of the economic difficulty of taking horizontal architecture into account in regions with high population density. According to the regulation of TBDY2018, special principles are included in the design of such high-rise buildings. In this study, a reinforced concrete highrise building was designed to provide sufficient strength. It is aimed to detail the rules to be followed during the design phase. For this reason, the reinforced concrete building model was created with the help of ETABS2019 computer package program and nonlinear analysis in time history was carried out using FNA (Fast Nonlinear Analysis) method. The data obtained from the analyses were presented and evaluated in graphs and tables. It has been observed that the designed reinforced concrete building model meets the criteria and performance target required in the regulation. In the next stage of the study, evaluation will be made using the direct integration method.
\end{abstract}

Keywords: FNA, TBDY-2018, Reinforced Concrete Tall Buildings.

\section{Giriş}

Günümüzde artan nüfus yoğunluğu nedeniyle yerleşim bölgelerinde dikey mimari tercih edilmektedir. Bu nedenle tasarlanan ve inşa edilen binalar genellikle yüksek binalar sınıfına dahil

*Corresponding author: Address: Faculty of Engineering, Department of Civil Engineering Karabuk University, 78050, Karabuk TURKEY. E-mail address: zsulegarip@ karabuk.edu.tr, Phone: +903704187057 
olmaktadır. Yüksek binalar yerleşim bölgelerinde kültürel yapıyı simgelemektedir. Birçok ülkede yüksek yapıların mimari özellikleri turizm açısından ciddi bir kazanım sağlamaktadır. 70 li yıllar itibarı ile Türkiye de yüksek bina yönelimi söz konusudur. Bu yönelim büyükşehirlerde özellikle İstanbul İlinde yoğunlaşmış ve bina yükseklikleri $200 \mathrm{~m}$ üzerine çıkmıştır [1]. Yükssek binalarda deprem etkisinin yapı yüksekliği ile orantılı olduğu bilinmektedir. 2008 İstanbul Yüksek Binalar Deprem Yönetmeliği ile tasarım aşaması için özel kurallar belirlenmiştir ancak bu kurallar İstanbul ili ile sınırlandırılmıştır. 1 Ocak 2019 tarihinden sonra yürürlüğe giren TBDY-2018 yönetmeliğinde yüksek binalar için ayrı bir bölüm bulunmakta ve tasarım koşulları detaylandırılmaktadır [2]. Bu çalışmada 36 katlı yüksek süneklikli betonarme bir binanın tasarımı TBDY2018 doğrultusunda gerçekleştirilmiş ve taşıyıcı sistemi perde duvarlı çerçeve sistem olarak tasarlanmıştır. Yapılan literatür taramasında yüksek binalar hakkında birçok çalışma incelenmiştir [3,10]. Bu çalışmaların birçoğunun TBDY2018 den önce olması nedeniyle yapılan bu çalışmanın literatüre katkı sağlayacağı kanaatine varılmıştır.

\section{Analizlerde Kullanılan Parametreler}

\subsection{Deprem Parametreleri}

Bu çalışmada konut tipi betonarme bina modelinin taşıyıı sistemi perde duvarlı ve çerçeveli sistem olarak modellenmiştir. Bina modelinin yer aldığ 1 bölge olarak deprem tasarım sınıfı 1 (DTS1) olacak şekilde enlem $40.903904^{\circ}$, boylam $29.332602^{\circ}$ seçilerek İstanbul İli tercih edilmiştir.

Betonarme bina modelinin analizlerinde kullanılan deprem tasarım sınıfı için gerekli olan spektral ivme katsayıları, ZC zemin sınıfında ve koordinatlar kullanılarak Türkiye Deprem Tehlike haritasından elde edilmiştir ve Tablo 1 de sunulmuştur [11].

Tablo 1. Analizlerde kullanılmak üzere seçilen konumun spektral değgerleri.

\begin{tabular}{|c|c|c|c|c|c|c|c|c|}
\hline DTS & $\begin{array}{l}\text { Seçilen } \\
\text { İl }\end{array}$ & $\begin{array}{c}\text { Enlem } \\
\text { Boylam }\end{array}$ & $\begin{array}{c}\text { Deprem Yer } \\
\text { Hareketi } \\
\text { Düzevi }\end{array}$ & $\begin{array}{l}S_{S} \\
S_{1}\end{array}$ & $\begin{array}{l}F_{S} \\
F_{1}\end{array}$ & $\begin{array}{l}S_{D S} \\
S_{D 1}\end{array}$ & $\begin{array}{l}P_{G A} \\
P_{G V}\end{array}$ & $\begin{array}{l}T_{A} \\
T_{B}\end{array}$ \\
\hline \multirow{4}{*}{ DTS1 } & \multirow{4}{*}{ İstanbul } & \multirow{4}{*}{$\begin{array}{l}40.903904 \\
29.332602\end{array}$} & DD1 & $\begin{array}{l}1.724 \\
0.501\end{array}$ & $\begin{array}{l}1.200 \\
1.499\end{array}$ & $\begin{array}{l}2.069 \\
0.751\end{array}$ & $\begin{array}{c}0.691 \\
43.978\end{array}$ & $\begin{array}{l}0.073 \\
0.363\end{array}$ \\
\hline & & & DD2 & $\begin{array}{l}0.983 \\
0.276\end{array}$ & $\begin{array}{l}1.200 \\
1.500\end{array}$ & $\begin{array}{l}1.180 \\
0.414\end{array}$ & $\begin{array}{c}0.403 \\
24.889\end{array}$ & $\begin{array}{l}0.070 \\
0.351\end{array}$ \\
\hline & & & DD3 & $\begin{array}{l}0.394 \\
0108\end{array}$ & $\begin{array}{l}1.300 \\
1500\end{array}$ & $\begin{array}{l}0.512 \\
0162\end{array}$ & $\begin{array}{c}0.171 \\
10377\end{array}$ & 0.063 \\
\hline & & & DD4 & $\begin{array}{l}0.267 \\
0.071\end{array}$ & $\begin{array}{l}1.300 \\
1.500\end{array}$ & $\begin{array}{l}0.347 \\
0.106\end{array}$ & $\begin{array}{l}0.116 \\
6.937\end{array}$ & $\begin{array}{l}0.061 \\
0.307\end{array}$ \\
\hline
\end{tabular}

DTS1 e ait Yatay Elastik Tasarım Spektrumları Şekil 1'de verilmiştir. DD3-DD4 e ait tasarım spektrum eğrileri yakın değerler alırken DD1-DD2 için elde edilen spektral ivme değerinin diğerlerine kıyasla büyük değerler aldığı görülmektedir. Bu bilgiler 1şı̆̆ında TBDY2018 de yüksek binaların tasarım aşamalarında DD1-DD2 ve DD4 kullanılması gerektiği belirtilmektedir. 


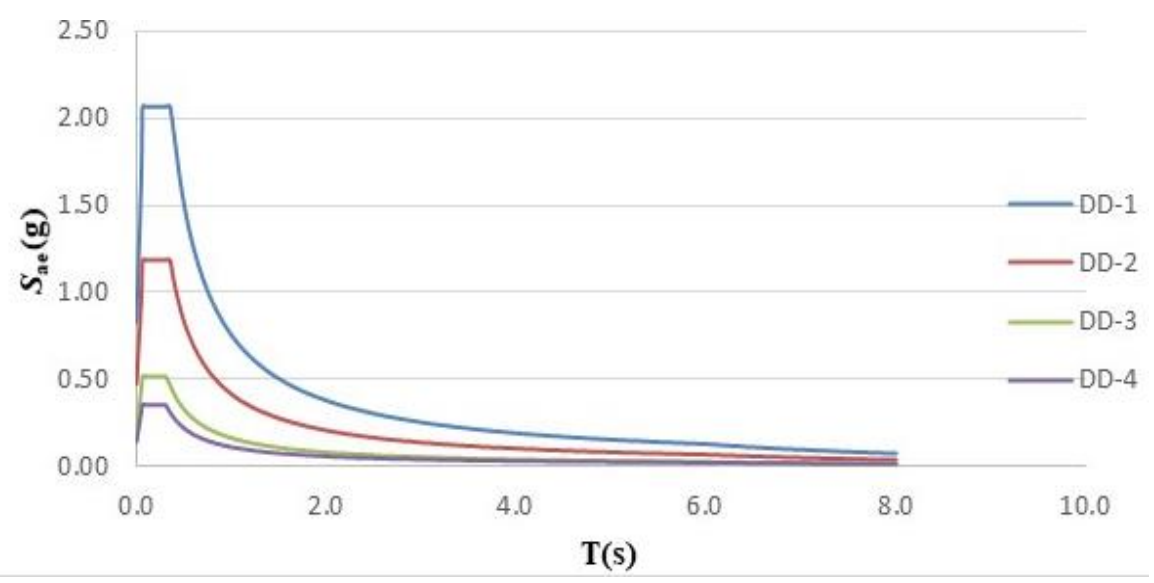

Şekil 1. Deprem Yer Hareketi Düzeylerine ait Yatay Elastik Tasarım Spektrumu

\subsection{Betonarme Bina Bilgileri}

Betonarme bina modeli ETABS2019 bilgisayar paket programı yardımıyla oluşturulmuş ve zaman tanım alanındaki analizleri FNA (Fast Nonlinear Analysis) yöntemi kullanılarak gerçekleştirilmiştir [12]. Betonarme bina modellerinin tasarımında dikkate alınan genel bilgiler Tablo 2 de verilmiştir.

Çalışmada incelenen betonarme bina modelinin kalıp planı ve üç boyutlu görünümü Şekil 2 de verilmiştir.

Betonarme bina modelinin kat planı rijit diyafram etkisi gösterecek şekilde simetrik ve $1600 \mathrm{~m} 2$ oturma alanlı olarak tasarlanmıştır. Çalışma kapsamında dikdörtgen geometrili perde duvarlar, burulma düzensizliğinin önüne geçebilmek adına simetrik olacak şekilde yeterli sayıda ve boyutta planda yerleştirilmiştir.

36 katlı betonarme bina modelinde kat yüksekliği tüm katlarda 3 m seçilmiştir. Bina yüksekliği 108 m olduğu için bina modeli TBDY2018 e göre yüksek binalar (BYS1) sınıfına girmektedir. Kat planında her iki doğrultuda 5 metrelik 8 açıklıktan oluşmaktadır. Bina modelinin taşıyıcı sistem eleman boyutlarında kat sayısının artışı ile gruplandırma yapılmış ve detayları Tablo 3 de verilmiştir.

Tablo 2. Analizlerde kullanılan genel bilgiler.

\begin{tabular}{|c|c|}
\hline Bina Yükseklik Sınıfı (BYS) & 1 \\
\hline Bina Kullanım Sınıfı (BKS) & 3 \\
\hline Bina Önem Katsayısı (I) & 1 \\
\hline Zemin Sinıfi & $\begin{array}{l}\text { ZC (Çok sık1 kum, çakıl ve sert kil } \\
\text { tabakaları veya ayrışmış, çok çatlaklı } \\
\text { zayıf kayalar) }\end{array}$ \\
\hline Beton Sinıfi & $\mathrm{C} 50 / 60 \quad \mathrm{E}=37000 \mathrm{~N} / \mathrm{mm}^{2}$ \\
\hline Donatı Sinıfi & $\mathrm{E}=200000 \mathrm{~N} / \mathrm{mm}^{2}$ \\
\hline \multicolumn{2}{|l|}{ Yükler: } \\
\hline Döşeme Kaplama Yükü & $1.75 \mathrm{kN} / \mathrm{m} 2$ \\
\hline Duvar Yükü & $2.90 \mathrm{kN} / \mathrm{m}$ \\
\hline Hareketli Yük & $2.00 \mathrm{kN} / \mathrm{m} 2$ \\
\hline
\end{tabular}


Tablo 3. Taşıyıcı Sistem Eleman Boyut Değişimi.

\begin{tabular}{ccccc} 
Elemanlar & $\mathbf{1 - 9}$ & $\mathbf{1 0 - 1 8}$ & $\mathbf{1 9 - 2 7}$ & $\mathbf{2 8 - 3 6}$ \\
\hline Perde Duvarlar $(\mathrm{cm})$ & $55 \times 500$ & $50 \times 500$ & $45 \times 500$ & $40 \times 500$ \\
\hline Kolonlar $(\mathrm{cm})$ & $110 \times 110$ & $100 \times 100$ & $90 \times 90$ & $80 \times 80$ \\
\hline Kirişler $(\mathrm{cm})$ & $60 \times 80$ & $60 \times 80$ & $50 \times 70$ & $50 \times 70$
\end{tabular}
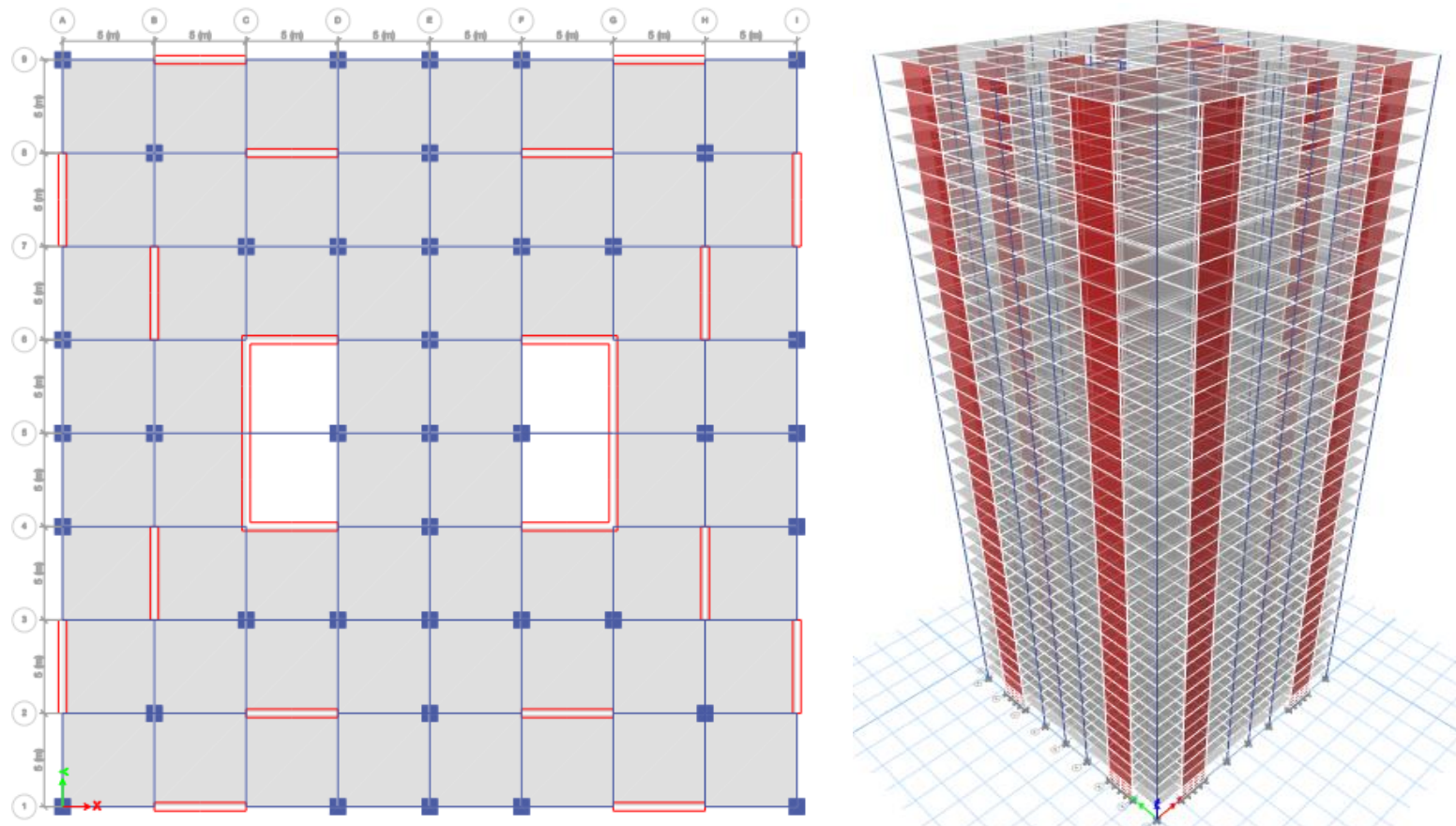

Şekil 2. Betonarme bina modeline ait kat planı ve üç boyutlu görünümü

\section{Tasarım Aşamaları}

TBDY2018 de yüksek binaların tasarımı için üç aşamalı tasarım önerilmiştir ve Tablo 4 de verilmiştir. DD1-DD2 ve DD4 için elde edilen spektral değerler kullanılarak her tasarım aşaması için normal performans hedefleri belirlenmiştir.

Tablo 4. Yeni Yapılacak Yüksek Binalar (BYS=1) Performans Hedefleri ve Değerlendirme/Tasarım Yaklaşımları. [2]

\begin{tabular}{ccc}
\multirow{2}{*}{$\begin{array}{c}\text { Deprem Yer } \\
\text { Hareketi Düzeyi }\end{array}$} & $\begin{array}{c}\text { Normal } \\
\text { Performans } \\
\text { Hedefi }\end{array}$ & $\begin{array}{c}\text { Değerlendirme/Tasarım } \\
\text { Yaklaşımı }\end{array}$ \\
DD4 & KK & DGT \\
DD3 & $---4 a$ \\
DD2 & KH & --- \\
DD1 & GÖ & DGT \\
ŞGDT
\end{tabular}

\subsection{Tasarım Aşaması I (ÖN TASARIM)}

Betonarme bina modeli DD2 deprem yer hareketi düzeyi altında Kontrollü Hasar (KH) performans 
hedefinin sağlayacak şekilde dayanıma göre tasarlanmıştır ve tasarım için TBDY2018 e göre tercih edilen opsiyonlar sunulmuştur. Tasarımda kolon ve kirişler çubuk eleman olarak, perde ve döşemeler kabuk elemanlar olarak modellenmiştir. Bina modelinde A2 ve A3 türü düzensizliklerinin bulunmamasından dolayı rijit diyafram olarak dikkate alınmıştır. Tasarım aşamasında TBDY2018 de belirtilen etkin kesit rijitlik çarpanları kullanılmıştır.

Bina modelinin taşıyıcı sistemi süneklik düzeyi yüksek perde duvarlar ve çerçeve sistemlerden oluşturulduğu için Taşıyıcı sistem davranış katsayısı 7 olarak alınması gerekirken TBDY2018 4.3.2.4-b maddesi uyarınca $(4 / 5) \mathrm{R}=5.6$ dikkate alınmıştır. Dayanım fazlalığı katsayısı aynen kullanılmıştır. Minimum taban kesme kuvveti şartı uygulanmıştır. Analizden elde edilen veriler kullanarak düzensizlik kontrolleri gerçekleştirilmiştir. Ayrıca göreli kat ötelemeleri ve ikinci mertebe etkileri kontrol edilmiştir. Bu aşamada düşey deprem etkisi özel bir hesap yapılmaksızın yönetmelik gereği $E_{d}^{Z} \approx(2 / 3) S_{D S} G$ dikkate alınarak $E_{d}^{Z}=0.78667 \times G$ hesaplamalara dahil edilmiştir. $\mathrm{Bu}$ aşamada sönüm oranı \%5 olarak alınmıştır. Yapılan değerlendirmeler 1şı̆̆ında betonarme bina modelinin Kontrollü Hasar $(\mathrm{KH})$ performans hedefini sağladığı belirlenmiş ve ikinci tasarım aşamasına geçilmiştir.

\subsection{Tasarım Aşaması II (İYILEŞTIRME)}

Betonarme bina modeli DD4 deprem yer hareketi düzeyi altında Kesintisiz Kullanım (KK) performans hedefinin sağlayacak şekilde dayanıma göre analiz edilmiştir. Tasarım aşamasında TBDY2018 de belirtilen II. Aşamada Uygulanacak Etkin Kesit Rijitliği Çarpanları kullanılmıştır.

Betonarme bina modelinin Mod Birleştirme yöntemi ile $R=1, I=1$ ve $D=1$ alınarak iç kuvvetleri hesap edilmiştir. Bu aşamada deprem yükleri ve diğer yükler için ek diş merkezlilik uygulanmamış ve malzeme karakteristik dayanımları yerine TBDY2018 de belirtilen beklenen (ortalama) malzeme dayanımları kullanılmıştır. Sönüm oranı \%2.5 olarak alınmıştır. Yapılan değerlendirmeler ışığında betonarme bina modelinin Kesintisiz Kullanım (KK) performans hedefini sağladığı belirlenmiş ve üçüncü tasarım aşamasına geçilmiştir.

\subsection{Tasarım Aşaması III (SON TASARIM)}

Betonarme bina modeli, DD1 deprem yer hareketi düzeyi altında Göçmenin Önlenmesi (GÖ) performans hedefinin sağlayacak şekilde zaman tanım alanında doğrusal olmayan hesap ile analiz edilmiştir. $\mathrm{Bu}$ aşamada kolon ve kirişlerde yığılı, perdelerde yayılı plastik davranış modeli kullanılmıştır. TBDY2018 doğrultusunda analizlerde \%2.5 Rayleigh orantılı sönüm matrisi kullanılmıştır.

\subsubsection{Deprem kayıtlarının seçimi ve ölçeklendirilmesi}

Zaman tanım alanında doğrusal olmayan hesapta kullanılmak üzere PEER [13] den $11(11 \times 2=22)$ adet doğrultu atımlı deprem kaydı elde edilmiştir. Seçilen deprem kayıtlarına ait bilgiler Tablo 5 de sunulmuştur. TBDY2018 de zaman tanım alanında doğrusal olmayan analiz için belirlenen deprem kayıtlarının basit ölçeklendirme ya da spektral uyuşum sağlanarak kullanılabileceği belirtilmektedir. Spektral uyuşumun kullanılabilmesi için dönüştürülen deprem yer hareketlerinin 
spektrumlarının ortalamaları, tüm periyotlar için tasarım spektrumu ordinatlarından daha küçük olmaması gerekmektedir. Bu çalışma kapsamında spektral uyuşum dikkate alınmıştır. Deprem kayıtlarının spektral uyuşumu SeismoMatch programı kullanılarak gerçekleştirilmiştir [14]. Depremlere ait orijinal ve uyuşum sağlanmış ivme kayıtları ve ortalama uyuşum spektrumu Şekil 3 ve Şekil 4 de sunulmuştur.

Tablo 5. Deprem Kayıtlarına Ait Özellikler. [13]

\begin{tabular}{lllllllll}
\hline & Depremler & RSN(s) & D5-95 (sn) & Şiddet & Rjb & Rrup & Vs(30) & Süre (sn) \\
\hline $\mathbf{1}$ & Parkfield & $\mathbf{2 8}$ & 29 & 6.19 & 17.64 & 17.64 & 408.93 & 44.29 \\
\hline $\mathbf{2}$ & Imperial Valley-06 & $\mathbf{1 6 4}$ & 36.4 & 6.53 & 15.19 & 15.19 & 471.53 & 63.81 \\
\hline $\mathbf{4}$ & Morgan Hill & $\mathbf{4 7 2}$ & 21.8 & 6.19 & 31.88 & 31.88 & 543.63 & 28.36 \\
\hline $\mathbf{5}$ & Chalfant Valley-02 & $\mathbf{5 5 1}$ & 19.2 & 6.19 & 29.35 & 31.19 & 382.12 & 39.99 \\
\hline $\mathbf{6}$ & Landers & $\mathbf{8 3 8}$ & 21.3 & 7.28 & 34.86 & 34.86 & 370.08 & 39.96 \\
\hline $\mathbf{7}$ & Big Bear-01 & $\mathbf{9 1 0}$ & 22.6 & 6.46 & 40.99 & 41.87 & 379.32 & 59.98 \\
$\mathbf{8}$ & Kocaeli, Turkey & $\mathbf{1 1 6 6}$ & 19.5 & 7.51 & 30.73 & 30.73 & 476.62 & 29.995 \\
\hline $\mathbf{9}$ & Düzce, Turkey & $\mathbf{1 6 1 6}$ & 20.5 & 7.14 & 23.41 & 23.41 & 517.00 & 43.15 \\
\hline $\mathbf{1 0}$ & Çaldıran, Turkey & $\mathbf{1 6 2 7}$ & 20.7 & 7.21 & 50.78 & 50.82 & 432.58 & 28.2 \\
\hline $\mathbf{1 1}$ & Hector Mine & $\mathbf{1 7 6 2}$ & 26.7 & 7.13 & 41.81 & 43.05 & 382.93 & 59.98 \\
\hline $\mathbf{1 3}$ & Chi-Chi, Taiwan-04 & $\mathbf{2 7 4 0}$ & 20.4 & 6.2 & 47.69 & 47.71 & 573.04 & 57.995 \\
\hline
\end{tabular}

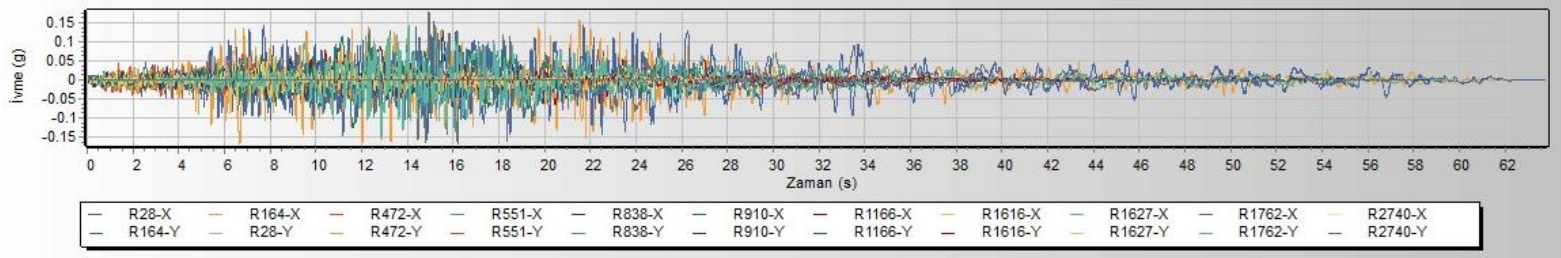

(a) Deprem kayıtlarına ait orijinal ivme zaman grafiği

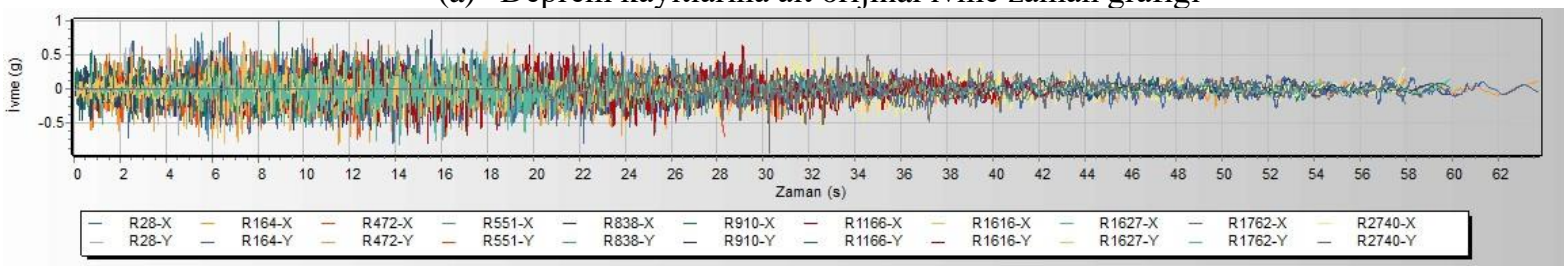

(b) Deprem kayıtlarına ait spektral uyuşum sağlanmış ivme zaman grafiği

Şekil 3. Deprem kayıtlarının ivme zaman grafikleri

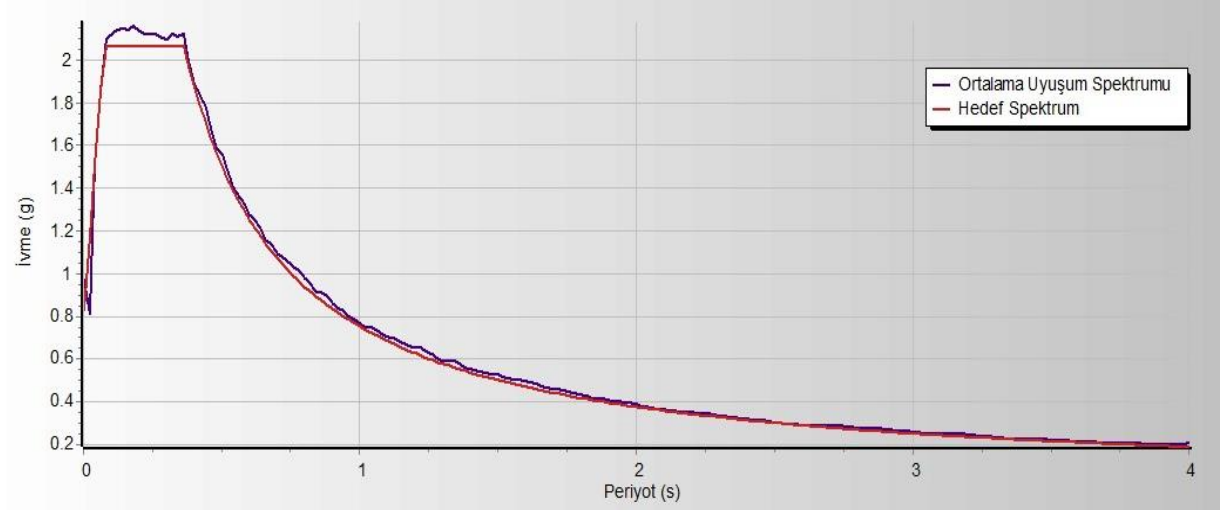

Şekil 4. Deprem kayıtlarına ait Ortalama Uyuşum Spektrumu 


\subsubsection{Performans dĕgerlendirmesi}

Kiriş ve Kolonların moment eğrilik eğrileri Sap2000 bilgisayar paket programı yardımıyla elde edilerek plastik sınır dönme değerleri hesaplanmıştır [15]. TBDY2018 de belirtilen kriterlere uygun olarak, kolon ve kirişlere ait plastik dönme değerleri Tablo 6 da, perde duvarlara ait beton birim kısalma ve donatı birim uzama sınır değerleri Tablo 7 de sunulmuştur.

Tablo 6. Kolon ve Kirişlere ait Plastik Dönme Değgerleri

\begin{tabular}{|l|c|c|c|}
\hline ELEMAN & $\boldsymbol{\theta}_{\mathbf{p}}^{(G 0 ̈)}$ & $\boldsymbol{\theta}_{\mathbf{p}}^{(\boldsymbol{K H})}$ & $\boldsymbol{\theta}_{\mathbf{p}}^{(\boldsymbol{S H})}$ \\
\hline C110X110 & 0.0310 & 0.0233 & 0 \\
\hline C100X100 & 0.0321 & 0.0241 & 0 \\
\hline C90X90 & 0.0338 & 0.0253 & 0 \\
\hline C80X80 & 0.0363 & 0.0272 & 0 \\
\hline B60X80 & 0.0353 & 0.0265 & 0 \\
\hline B50X70 & 0.0349 & 0.0261 & 0 \\
\hline
\end{tabular}

Tablo 7. Perde Duvarlara ait Beton Birim Kısalma ve Donatı Birim Uzama Sinır Değerleri

\begin{tabular}{|l|c|c|c|c|c|c|}
\hline \multirow{2}{*}{ ELEMAN } & \multicolumn{3}{|c|}{ BETON } & \multicolumn{3}{c|}{ DONATI } \\
\cline { 2 - 7 } & $\boldsymbol{\varepsilon}_{\boldsymbol{c}}^{(G \ddot{)})}$ & $\boldsymbol{\varepsilon}_{\boldsymbol{c}}^{(\boldsymbol{K H} \boldsymbol{H})}$ & $\boldsymbol{\varepsilon}_{\boldsymbol{c}}^{(\boldsymbol{S H})}$ & $\boldsymbol{\varepsilon}_{\boldsymbol{s}}^{(G \ddot{O})}$ & $\boldsymbol{\varepsilon}_{\boldsymbol{s}}^{(\boldsymbol{K H} \boldsymbol{H})}$ & $\boldsymbol{\varepsilon}_{\boldsymbol{s}}^{(\boldsymbol{S H})}$ \\
\hline $\mathrm{P}(1-6)$ & 0.01362 & 0.01021 & 0.0025 & 0.0320 & 0.0024 & 0.0075 \\
\hline $\mathrm{P}(7-9)$ & 0.01271 & 0.00954 & 0.0025 & 0.0320 & 0.0024 & 0.0075 \\
\hline $\mathrm{P}(10-18)$ & 0.01248 & 0.00936 & 0.0025 & 0.0320 & 0.0024 & 0.0075 \\
\hline $\mathrm{P}(19-27)$ & 0.01242 & 0.00931 & 0.0025 & 0.0320 & 0.0024 & 0.0075 \\
\hline $\mathrm{P}(28-36)$ & 0.01225 & 0.00919 & 0.0025 & 0.0320 & 0.0024 & 0.0075 \\
\hline
\end{tabular}

\section{Değerlendirme:}

Betonarme bina modelinin $2 \times 11=22$ adet deprem kaydı ile gerçekleştirilen zaman tanım alanında doğrusal olmayan analizleri sonucunda taşıyıcı sistem elemanlarının çoğunun ileri hasar bölgesine ulaşmadığı görülmektedir (Şekil 5). Burada değerlendirme her analizden elde edilen talep değerlerinin en büyük mutlak değerlerinin ortalaması hesaplanarak sınır değerlerle karşılaştırılması şeklinde yapılmıştır. Dolayısıyla tasarlanan yüksek bina modelinin istenilen performans hedefini sağladığı belirlenmiştir. Ayrıca bina modelinde A1 burulma düzensizliği söz konusu değildir.

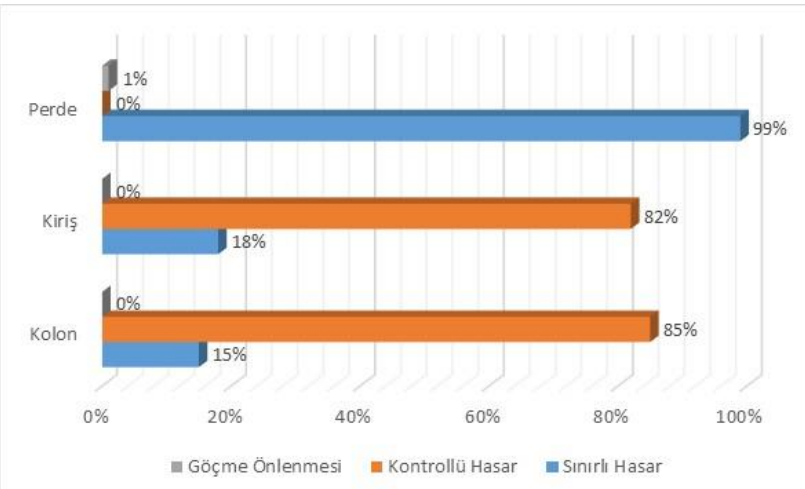

Şekil 5. Hasar Bölgelerindeki Eleman Yüzdeleri 
Göreli kat ötelemeleri için verilen sınır değerler iki şekilde verilmiştir. Herhangi bir katta tüm deprem kayıtlarından elde edilen ortalama göreli kat ötelemesi oranı 0.03 'ten daha büyük olmamalı ve tek bir deprem kaydından elde edilen en büyük göreli kat ötelemesi oran1 0.045 'ten daha büyük olmamalıdır. Analizlerden elde edilen sonuçlar Şekil 6 ve Şekil 7 de sunulmuştur. H1 doğrultusu 22 adet deprem yatay ivme kaydının normal doğrultularını, H2 doğrultusu $90^{\circ}$ döndürülmüş halini göstermektedir.
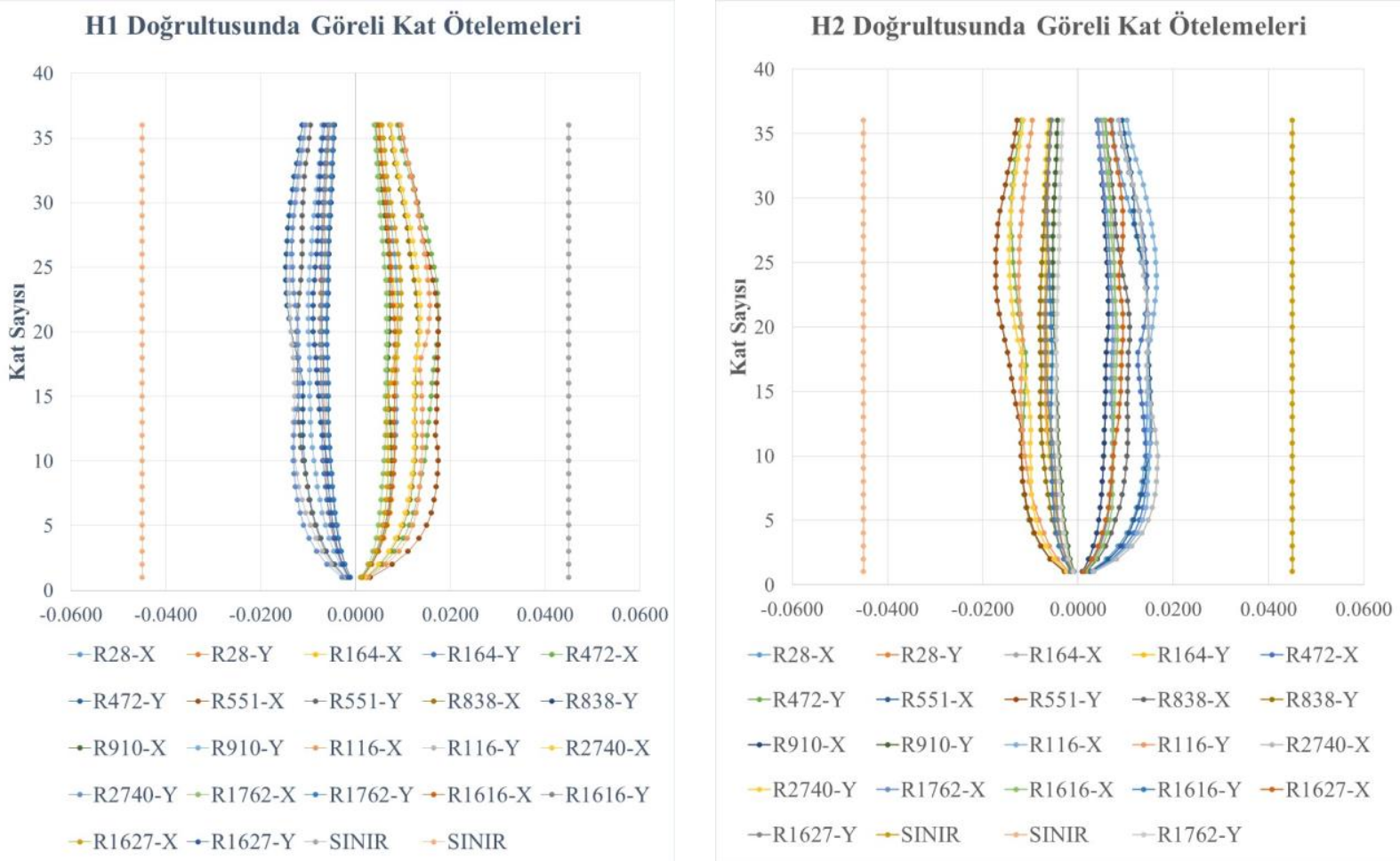

Şekil 6. Göreli Kat Ötelemeleri

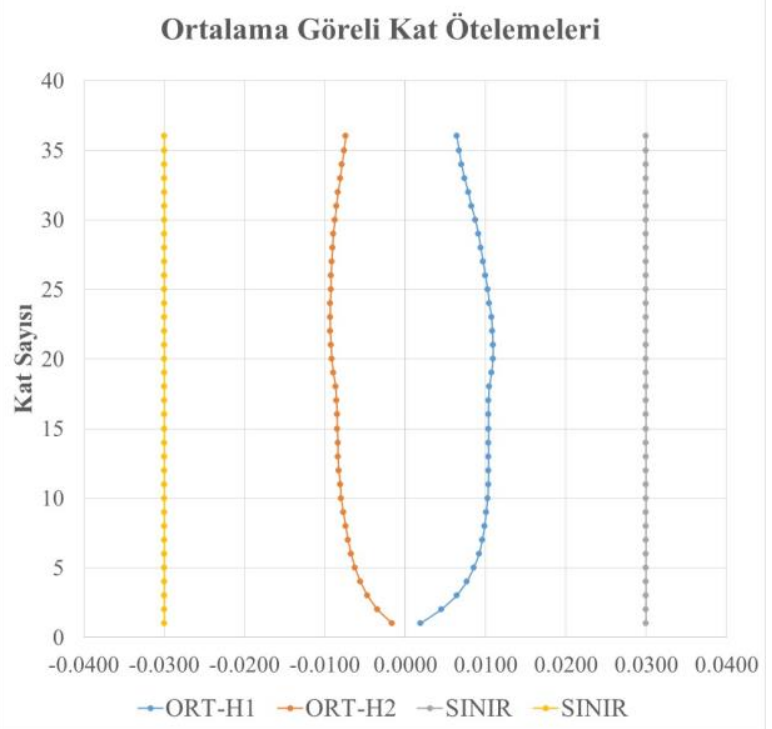

Şekil 7. Ortalama Göreli Kat Ötelemeleri 
Betonarme bina modelinin $2 \times 11=22$ adet deprem kaydı ile gerçekleştirilen zaman tanım alanında doğrusal olmayan analizleri sonucunda elde edilen taban kesme kuvvetleri Şekil 8 de sunulmuştur. Taban kesme kuvvetlerinin Deprem kayıtlarının yön değiştirmesi ile artış gösterdiği belirlenmiştir. Bina modelinin tasarımının birinci aşamasında hesaplanan minimum taban kesme kuvveti ile gerçek depremlerin etkisi altında hesaplanan taban kesme kuvvetleri karşılaştırıldığında yaklaşık olarak 11 kat artış gözlemlenmiştir.

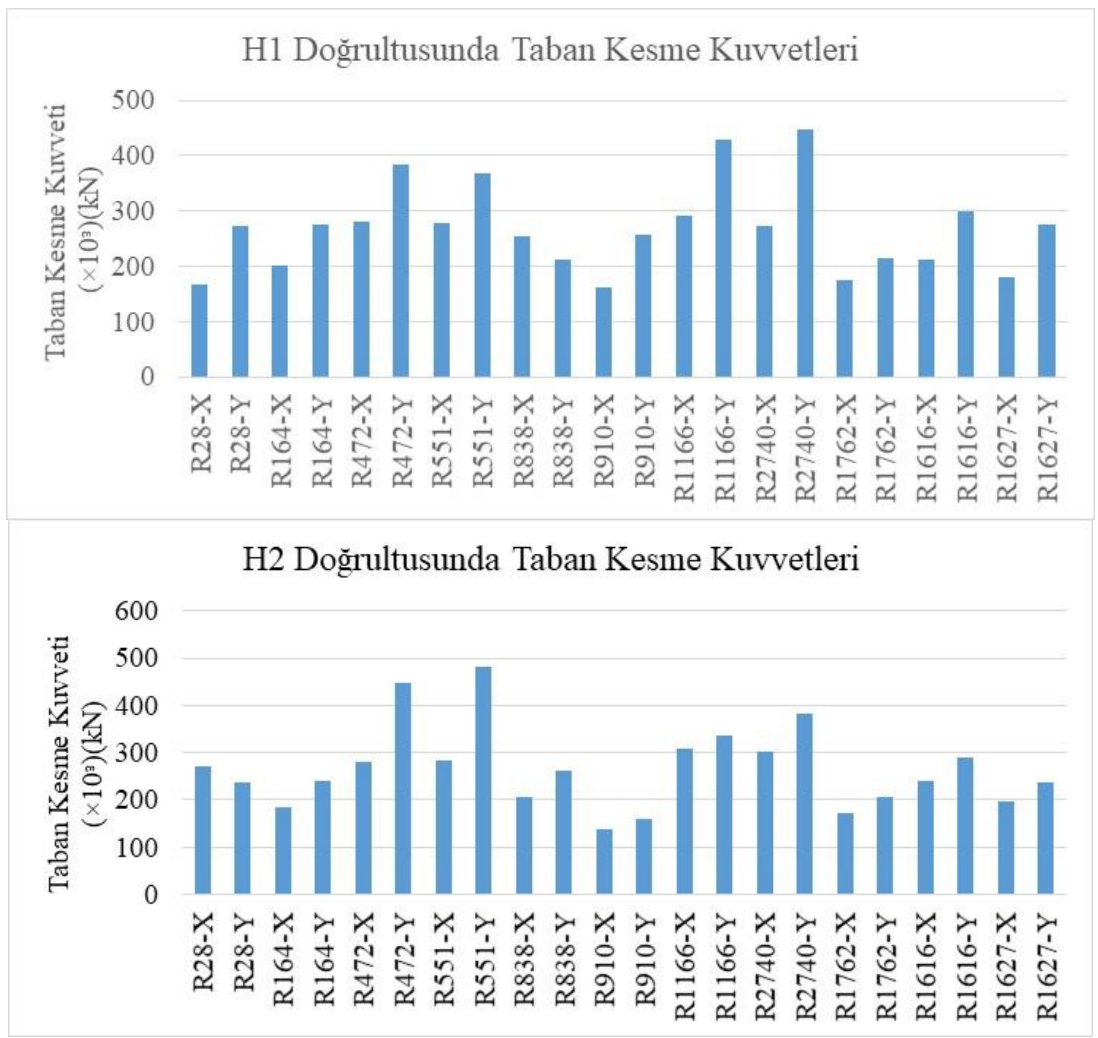

Şekil 8. Taban Kesme Kuvvetleri

\section{Sonuçlar:}

Bu çalışma kapsamında TBDY2018 de belirtilen kurallara bağlı olarak 36 katlı betonarme bina modeli tasarlanmış ve gerekli kontroller yapılarak tasarımı başarıyla gerçekleştirilmiştir. TBDY2018 den farklı olarak bu modelde zaman tanım alanında doğrusal olmayan hesapta doğrudan integrasyon yerine daha hızlı gerçekleştirilebilen FNA (Fast Nonlineer Analysis) yöntemi kullanılmıştır. Seçilen taşıyıcı sistem özelliklerine bağlı olarak bina modeli istenen performans hedefini ve dayanımı sağlamıştır. Ekonomik açıdan taşıyıcı sistemde kolon ve kirişlerin boyutlarının küçültülmesinin ve ileri hasar bölgesine geçen perde elemanının boyutunun arttırılmasının uygun olacağı belirlenmiştir. Diğer perde elemanları elastik sınırlar için kalmıştır.

Yapılan bu çalışmanın TBDY2018 de belirtildiği gibi zaman tanım alanında doğrudan integrasyon ile çözümü ileri ki çalışmalarda gerçekleştirilecektir. 


\section{Kaynaklar}

[1] Council on Tall Buildings and Urban Habitat, 02.01.2021, https://www.ctbuh.org/

[2] TBDY2018, Türkiye Bina Deprem Yönetmeliği, Afet ve Acil Durum Yönetimi Başkanlığg, Ankara, 1-395, 2018.

[3] Zekioğlu, A., Willford, M., Jin, L., Melek, M., "Case Study Using The Los Angeles Tall Buildings Structural Design Council Guidelines: 40-Storey Concrete Core Wall Building", Special Issue: Fourth Annual Special Issue - LA Tall Buildings Structural Design Council, The Structural Design of Tall and Special Buildings 16, 5, 583-597, 2007.

[4] Karaçöp, A., "Betonarme Bir Yüksek Binanın İstanbul Yüksek Binalar Deprem Yönetmeliğine Göre İncelenmesi”, Yüksek Lisans Tezi, Fen Bilimleri Enstitüsü, İstanbul Teknik Üniversitesi, 2010.

[5] Ali, S., "Static And Dynamic Analysis Of Multistory Building Including P- $\Delta$ Analysis", Yüksek Lisans Tezi, Gaziantep Üniversitesi, 2013.

[6] Al-luhaibi, M. S., "Design And Analysis Of A High-Rise Building Located In Two Different Seismic Zones Utilizing Istanbul Seismic Design Code For Tall Buildings (ISDCTB)", Yüksek Lisans Tezi, İstanbul Teknik Üniversitesi, 2017.

[7] Özaydın, Y., "30 Katlı Betonarme Yüksek Bir Binanın 2018 TBDY Kapsamında Tasarımı ve Performans Analizi”, Yüksek Lisans Tezi, İstanbul Teknik Üniversitesi, 2019.

[8] Eraslan, G., "Yüksek Binaların Deprem ve Rüzgâr Etkileri Altında Statik ve Dinamik Davranışının İncelenmesi”, Yüksek Lisans Tezi, Dokuz Eylül Üniversitesi, 2019.

[9] Çopuroğlu, A., "Yüksek Binalarda Düşey Yer Hareketinin Etkisi”, Yüksek Lisans Tezi, İstanbul Teknik Üniversitesi, 2019.

[10] Akçora, A. A., "Betonarme Yüksek Binaların 2018 Y1lı Türkiye Bina Deprem Yönetmeliğine Göre İncelenmesi: 30 Katlı Bina Örneği”, Yüksek Lisans Tezi, Yıldız Teknik Üniversitesi, 2020.

[11] AFAD, T.C. İçişleri Bakanlığı Afet ve Acil Durum Yönetimi Başkanlığı, Ankara, https://www.afad.gov.tr/turkiye-deprem-tehlike-haritasi, 2019.

[12] ETABS, Structural Analysis Program, Computers and Structures Inc., Berkeley, California, 2019.

[13] PEER, «PEER Strong Ground Motion Database,» Pasific Earthquake Research Center, [Çevrimiçi]. Available: http://peer.berkeley.edu/smcat/, 2021

[14] SEISMOMATCH, SeismoMatch - Earthquake Software for Response Spectrum Matching, https://seismosoft.com, 2021.

[15] SAP2000, Integrated Finite Element Analysis and Design of Structures Basic Analysis Reference Manual, Computers and Structures, Inc., California, 2019. 